\title{
Design of PID Controller for SISO and TITO Systems - A Study with Heuristic Algorithms
}

\author{
R. Manibharathi ${ }^{1}$, K. Manoj Kumar ${ }^{2}$, K. Kumaran ${ }^{3}$, Dr. N. Sri Madhava Raja ${ }^{4}$ \\ Department of Electronics and Instrumentation Engineering, \\ St. Joseph's College of Engineering, OMR, Chennai 600119. \\ Tamilnadu, India. \\ ${ }^{1}$ mani.barathi123@gmail.com \\ ${ }^{2}$ manojyendo95@gmail.com \\ ${ }^{3}$ kumaran1495@gmail.com \\ ${ }^{4}$ nsrimadhavaraja@stjosephs.ac.in
}

\begin{abstract}
This paper proposes a study on heuristic algorithms based PID controller design for a class of Single Input Single Output (SISO) and Two Input and Two Output (TITO) systems. In this work, well known heuristic methods such as Particle Swarm Optimization (PSO), Improved PSO (IPSO), Bacterial Foraging Optimization (BFO), hybrid algorithm (PSO+BFO) and Firefly Algorithm (FA) are chosen to find the optimal $K_{p}, K_{i}, K_{d}$ values based on the chosen SISO and TITO process models. For the SISO systems, the well known PID and set-point filter based PID controllers are implemented and for the TITO process models, a decentralised PID controller design is proposed. In this work, the optimization process is focused to search the best possible controller parameters $\left(K_{p}, K_{i}, K_{d}\right)$ by minimizing the multi objective performance index chosen to guide the heuristic search. The effectiveness of the proposed scheme has been confirmed through a comparative study with heuristic procedures and the classical controller tuning methods proposed in the literature. The results show that, heuristic algorithm assisted approach provides enhanced performance in effective reference tracking with minimal ISE and IAE values. Finally the robustness of the SISO system is validated by operating the unstable systems in the presence of a measurement noise. The results testify that the PSO-BFO tuned set-point filter based PID performs well in tracking the change in reference signal even in the noisy environment. The FA based procedure on the TITO system also offered better result on the TITO process compared with others approaches existing in the literature.
\end{abstract}

Keyword-PID controller, SISO system, MIMO system, Heuristic approaches, Performance analysis

\section{INTRODUCTION}

In chemical industry, most of the important processing units are highly non-linear in nature and for economical and/or safety reasons, these process loops to be operated in safe regions with the help of a PID controller [1-3]. Based on its operating region and its non-linearity, these loops can be modelled as SISO and MIMO systems. During the closed loop operation, optimized controller parameters for such systems are essential to minimize the waste and to maximize the production rate. Fine tuning the controller parameters for non-linear systems are highly complex than open loop stable systems. Hence, in recent years, heuristic algorithm assisted approaches are widely adopted by the researchers.

In recent years, many efforts have been attempted to design optimal and robust controllers for chemical systems [4 - 6]. Normally, most of these classical controller tuning approaches require an approximated transferfunction and state space model of the system around the operating point. In real time applications, the approximated model parameter may be changing or subject to uncertainty. Also the tuning method proposed for a particular model does not provide a satisfactory result on the other models. Hence, to overcome these issues, it is necessary to employ intelligent controller tuning procedures to identify the best possible controller parameters for the non-linear chemical systems.

In recent years, heuristic algorithm based optimization is emerged as a powerful tool for finding the solutions for a variety of control engineering problems. Recent work utilises the heuristic procedures, such as Particle Swarm Optimization [6, 7], Improved PSO [8], Bacterial Foraging Optimization [9, 10], Hybrid algorithm [11, 12], Bat Algorithm [13], Firefly Algorithm [14], Teaching Learning Based Optimization [15], etc. 
The work by Rajinikanth and Latha [6] reported that heuristic algorithm based PID controller tuning can be implemented for the unstable SISO system when the 'Delay/Time constant' ratio is below 0.2. PID based tuning results large overshoot which tends to increase the error and overshoot value, when this ratio is greater than 0.2 . This phenomenon disrupts the convergence of soft computing based search. In this work, the PID controller parameter tuning is proposed for a class of SISO and TITO chemical systems existing in the literature. A comparative study also carried out with the proposed heuristic approaches and the classical controller tuning methods proposed in the literature.

The remaining part of the paper is organized as follows: principle of various evolutionary algorithms and implementation of these algorithms to obtain optimized controller value is discussed in Section 2 and 3 respectively. In Section 4, results and discussions on a class of chemical system models are presented. Finally, the conclusion of the present research work is given in Section 5.

\section{HEURISTIC ALGORITHMS ADOPTED IN THIS PAPER}

This section presents the overview of the heuristic algorithms chosen for the study.

\section{A. Particle Swarm Optimization}

PSO is a population based stochastic optimization technique inspired by social behaviour of bird flocking or fish schooling, and it is widely used in engineering applications due to its high computational efficiency [16]. PSO algorithm is easy to implement and there are few parameters to adjust compared to other heuristic methods. It is a population based evolutionary computation technique, attempts to mimic the natural process of group communication of individual knowledge, to achieve some optimum property. More details regarding the PSO can be found in $[2,3]$.

The basic mathematical expression of the PSO is depicted below;

$$
\begin{aligned}
\mathrm{V}_{\mathrm{i}}^{\mathrm{t}+1} & =\mathrm{W}^{\mathrm{t}} \cdot \mathrm{V}_{\mathrm{i}}^{\mathrm{t}}+\mathrm{C}_{1} \cdot \mathrm{R}_{1} \cdot\left(\mathrm{P}_{\mathrm{i}}^{\mathrm{t}}-\mathrm{S}_{\mathrm{i}}^{\mathrm{t}}\right)+\mathrm{C}_{2} \cdot \mathrm{R}_{2} \cdot\left(\mathrm{G}_{\mathrm{i}}^{\mathrm{t}}-\mathrm{S}_{\mathrm{i}}^{\mathrm{t}}\right) \\
S_{i}^{t+1} & =S_{i}^{t}+V_{i}^{t+1} \\
\mathrm{~W}^{\mathrm{t}} & =\left(\mathrm{W}_{\max }-\text { Iter }\right) \mathrm{x} \frac{\left(\mathrm{W}_{\max }-\mathrm{W}_{\min }\right)}{\text { Iter }_{\max }}
\end{aligned}
$$

Where, $C_{1}, C_{2}$ are positive constants. $C_{1}$ is the cognitive learning rate and $C_{2}$ is the global learning rate. $R_{1}$, $\mathrm{R} 2$ are random numbers in the range $0-1$. The parameter ' $\mathrm{W}$ ' is inertia weight that increases the overall performance of PSO. The larger value of ' $\mathrm{W}$ ' can favour the global wide-range search and lower value of ' $\mathrm{W}$ ' implies a higher ability for local nearby search.

\section{B. Improved PSO Algorithm}

Chang and Shih [8] have developed an IPSO algorithm to tune the PID controller for a non linear inverted pendulum system. In this, an improved velocity updating equation is proposed to improve the algorithm convergence and it is given in Eqn .4.

$\mathrm{V}_{\mathrm{i}}^{(\mathrm{t}+1)}=\mathrm{W}^{\mathrm{t}} \cdot \mathrm{V}_{\mathrm{i}}^{\mathrm{t}}+\mathrm{C}_{1} \cdot \mathrm{R}_{1} \cdot\left(\right.$ pbest $\left.-\mathrm{S}_{\mathrm{i}}^{\mathrm{t}}\right)+\mathrm{C}_{2} \cdot \mathrm{R}_{2} \cdot\left(\right.$ gbest $\left.-\mathrm{S}_{\mathrm{i}}^{\mathrm{t}}\right)+\mathrm{C}_{3} \cdot \mathrm{R}_{3} \cdot\left(\right.$ ibest $-\mathrm{S}_{\mathrm{i}}^{\mathrm{t}}$ )

Where, 'ibest' represents the best particle's position among all particles in the sub-population that the $i^{\text {th }}$ particle belongs to. $\mathrm{C}_{3}$ and $\mathrm{R}_{3}$ are positive constant and random number respectively.

\section{Bacterial Foraging Optimization}

BFO algorithm is a biologically inspired stochastic search technique based on mimicking the foraging behavior of E.coli bacteria [17]. During foraging, a bacterium can exhibit two different actions: Tumbling or swimming. The tumble action modifies the orientation of the bacterium. During swimming (chemotactic step) the bacterium will move in its current direction. Chemotactic movement is continued until a bacterium goes in the direction of positive nutrient gradient. After a certain number of complete swims, the best half of the population undergoes reproduction, eliminating the rest of the population. In order to escape local optima, an elimination-dispersion event is carried out where, some bacteria are liquidated at random with a very small probability and the new replacements are initialized at random locations of the search space. 
In this work, enhanced BFO discussed in [1,4] is adopted; Number of E. Coli bacteria $=N$

$N_{c}=\frac{N}{2} ; N_{s}=N_{r e} \approx \frac{N}{3} ; N_{e d} \approx \frac{N}{4} ; N_{r}=\frac{N}{2} ; P_{e d}=\left(\frac{N_{e d}}{N+N_{r}}\right) ; \mathrm{d}_{\mathrm{att}}=\mathrm{W}_{\text {att }}=\frac{N_{S}}{N} ;$ and $\mathrm{h}_{\text {rep }}=\mathrm{W}_{\text {rep }}=\frac{N_{C}}{N}$

\section{Hybrid Optimization Algorithm}

This algorithm was proposed by Korani et al. [11] to improve the performance of BFO. In this method, the cost function (ISE) is applied for both the PSO and BFO algorithm. The PSO algorithm monitors the BFO to achieve a minimum convergence time with optimized parameters. In hybrid algorithm, after undergoing a chemotactic step, each bacterium gets mutated by a PSO operator. The PSO operator considers only the 'social' component and eliminates the 'cognitive' component. In this algorithm, due to the information sharing between the PSO and $\mathrm{BFO}$, the hybrid algorithm can provide the optimized solutions with minimal convergence time compared to a conventional BFO algorithm.

\section{E. Firefly algorithm}

The classical Firefly Algorithm (FA) was initially proposed by Yang [18]. FA is a nature inspired metaheuristic algorithm, in which flashing illumination patterns generated by fireflies are modelled using a suitable mathematical expression. In this work, the recent version of the FA discussed in $[19,20]$ is considered.

The association of an attracted firefly towards a mate can be expressed as:

$$
X_{i}^{t+1}=X_{i}^{t}+\beta_{0} e^{-\gamma d_{i j}^{2}}\left(X_{j}^{t}-X_{i}^{t}\right)+\alpha^{1}(\text { rand }-1 / 2)
$$

where $X_{i}^{t}$ is early location; $X_{i}^{t+1}$ is updated location; $\beta_{0} e^{-\gamma d_{i j}^{2}}\left(X_{j}^{t}-X_{i}^{t}\right)$ is attraction among fireflies; $\beta 0$ is preliminary attractiveness; $\gamma$ is absorption coefficient; $\alpha^{l}$ is randomization operator and rand is random number $[0,1]$. In this paper, the following values are chosen for FA parameters: $\alpha^{l}=0.15 ; \beta_{0}=0.1$ and $\gamma=1$.

\section{IMPLEMENTATION}

The chosen problem is to design the PID controller for the process models. A generalized close loop control system is depicted in Fig.1. The controller ' $\mathrm{G}_{\mathrm{c}}(\mathrm{s})$ ' has to provide closed loop stability, smooth reference tracking and load disturbance rejection $[21,22]$.

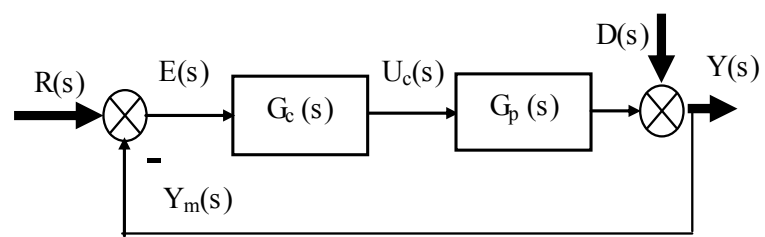

Fig. 1. Block diagram of a closed loop control system

Closed loop response of the above system with set-point ' $R(s)$ ' and disturbance ' $D(s)$ ' can be expressed as;

$Y(s)=\left[\frac{G_{p}(s) G_{C}(s)}{1+G_{p}(s) G_{C}(s)}\right] R(s)+\left[\frac{1}{1+G_{p}(s) G_{C}(s)}\right] D(s)$

The final steady state response of the system for the reference tracking and the disturbance rejection is presented in Eqn. 3 and Eqn. 4 correspondingly.

$$
\begin{aligned}
& Y_{R}(\infty)=\operatorname{lims}_{t \rightarrow \infty} Y_{R}(s)=\lim _{t \rightarrow \infty} x\left[\frac{G_{p}(s) G_{C}(s)}{1+G_{p}(s) G_{C}(s)}\right]\left(\frac{A}{s}\right)=A \\
& Y_{D}(\infty)=\lim _{t \rightarrow \infty} x\left[\frac{1}{1+G_{p}(s) G_{C}(s)}\right]\left(\frac{L}{s}\right)=0
\end{aligned}
$$

Where: $\quad \mathrm{A}=$ amplitude of reference signal $; \mathrm{D}=$ disturbance

To achieve a satisfactory $Y_{R}(\infty)$ and $Y_{D}(\infty)$, it is necessary to have optimally tuned values for $K_{p}, K_{i}$ and $K_{d}$. In this study, a non-interacting form of parallel PID controller is considered to achieve the preferred response. 
The parallel PID structure is given below:

$$
\begin{aligned}
& G_{C}(s)=K_{p} e(t)+K_{i} \int_{0}^{T} e(t) d t+K_{d} \frac{d e(t)}{d t} \\
& G_{P I D}(s)=K_{p}\left[1+\frac{1}{T_{i} s}+T_{d} s\right]
\end{aligned}
$$

Where: $\mathrm{K}_{\mathrm{p}} / \mathrm{T}_{\mathrm{i}}=\mathrm{K}_{\mathrm{i}} ; \mathrm{Kp}^{*} \mathrm{~T}_{\mathrm{d}}=\mathrm{K}_{\mathrm{d}}$.

For the filtered PID, the filter time constant is chosen as the Ti [23].

The multiple objective function for controller optimization was chosen. In this work performance criterion with four functions, such as $\mathrm{CF}, \mathrm{M}_{\mathrm{p}}, \mathrm{t}_{\mathrm{s}}$, and $\mathrm{E}_{\mathrm{ss}}$ as presented below was chosen to guide the heuristic search

$\mathrm{J}_{\min }\left(\mathrm{K}_{\mathrm{p}}, \mathrm{K}_{\mathrm{i}}, \mathrm{K}_{\mathrm{d}}\right)=\left(\mathrm{w}_{1} \cdot \mathrm{E}_{\mathrm{ss}}+\left(\mathrm{w}_{2} \cdot \mathrm{t}_{\mathrm{s}}\right)+\left(\mathrm{w}_{3} \cdot \mathrm{M}_{\mathrm{p}}\right)\right.$

Where:

$\mathrm{w}_{1} \cdot \mathrm{w}_{2}, \mathrm{w}_{3}$-weighting parameters (range is from $0-1$ ), $\quad \mathrm{E}_{\mathrm{ss}}$ - the steady state error, $\mathrm{t}_{\mathrm{s}}-$ settling time and $\mathrm{M}_{\mathrm{p}}$ - overshoot.

The PID tuning process is employed to find the best possible values for $\mathrm{K}_{\mathrm{p}}, \mathrm{K}_{\mathrm{i}}$ and $\mathrm{K}_{\mathrm{d}}$ and the set-point filter parameter ' $\mathrm{T}_{\mathrm{f}}$ ' form the three dimensional search space by minimizing the objective function. During this search, the performance criterion ' $\mathrm{J}_{\min }\left(\mathrm{K}_{\mathrm{p}}, \mathrm{K}_{\mathrm{i}}, \mathrm{K}_{\mathrm{d}}\right)$ ' guides the heuristic algorithm to get appropriate values for the controller parameters.

\section{RESULTS AND DISCUSSIONS}

This section presents the results obtained with the proposed approach. All the simulations are implemented using the MATLAB software. In this work, the proposed controller design procedure is implemented on the well known SISO and TITO process loops. During the simulation work, the following values are assigned for the algorithm parameters: number of agents $(\mathrm{N})=30$, dimension of the search $(\mathrm{D})=3$, stopping criteria $=\mathrm{J}_{\min }$ and the number of iterations $=1000$.

\section{a. SISO systems}

Process 1: The first order plus delayed time unstable process with the following transfer function model is considered [24-27];

$$
\mathrm{G}_{\mathrm{p}}(\mathrm{s})=\frac{4 \mathrm{e}^{-2 \mathrm{~s}}}{4 \mathrm{~s}-1}
$$

The process has a gain $(K)=4$, process time constant $(\tau)=4$ and time delay $(d)=2$. For this process $d / \tau$ is 0.5 . Many studies have proposed different PID settings for the above model and the values are clearly presented in the literature. The classical PID settings are presented in Table 1.

The evolutionary algorithm based controller tuning is proposed for the system as in Fig. 2.

The final convergence of the controller parameters for the hybrid algorithm is shown in Fig. 3 and the optimised $\mathrm{K}_{\mathrm{p}}, \mathrm{K}_{\mathrm{i}}, \mathrm{K}_{\mathrm{d}}$ values are tabulated in Table 1. Fig. 4 shows the convergence of the CF for the various evolutionary search algorithms. Fig.5 depicts the servo response of the process with classical PID settings proposed in the literature. In this The HC [24] method shows a satisfactory result compared to other methods. Fig.6 shows the reference tracking performance of the evolutionary methods. The observation is that, the hybrid method provides a good result for reference tracking performance.

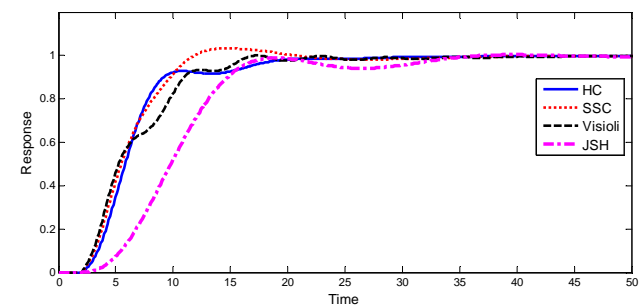

Fig. 2. Servo responses for Process 1 with classical PID parameters 


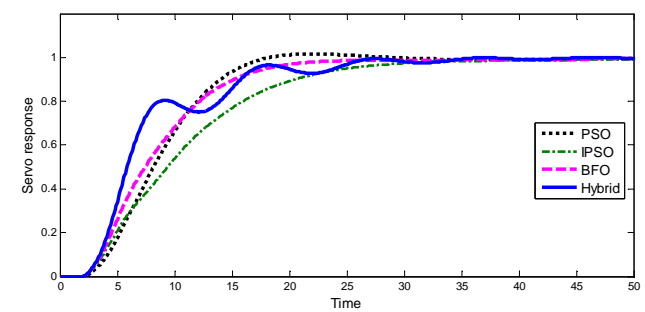

Fig. 3. Servo responses for Process 1 with optimised PID parameters

From Table 1, it is observed that, the hybrid algorithm based tuning has less number of iteration (67) and it also shows a good performance measure in reference tracking (such as: ISE, IAE, $\mathrm{M}_{\mathrm{p}}$ and $\mathrm{T}_{\mathrm{s}}$ ) compared to PSO, IPSO and BFO algorithms.

Process 2: The second order delayed unstable process with the following transfer function is considered. It has one unstable pole and a stable pole $[24,28]$.

$$
\mathrm{G}_{\mathrm{p}}(\mathrm{s})=\frac{\exp ^{-\mathrm{s}}}{(2 \mathrm{~s}-1)(0.5 \mathrm{~s}+1)}
$$

Previous studies have proposed different PID settings for the above model (Huang and Chen, 1999; Lee, Lee, and Park, 2000). Fig.7. shows the servo response of the previous work reported in literature. In this diagram, the method proposed by LLP provides the smooth reference tracking performance compared to PC and HC. Fig.8. shows the reference tracking performance of the present study. The response produced by the PSO and IPSO algorithm is more oscillatory compared to BFO and PSO-BFO methods.

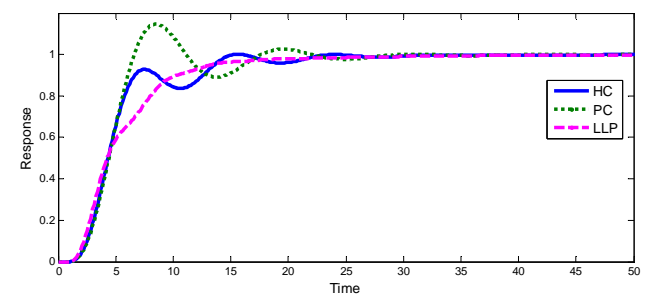

Fig. 4. Servo responses for Process 2 with conventional PID parameters

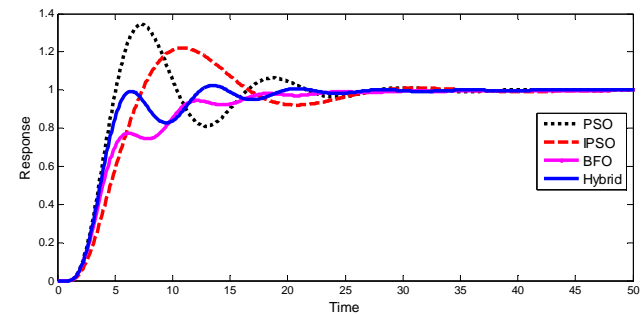

Fig. 5. Servo responses for Process 2 with soft computing based PID parameters

From Fig.5 and Table 1, it is inferred that, the proposed hybrid method can be used to get an optimal controller parameter with lesser convergence time to provide a smooth reference tracking performance than other optimisation algorithms.

TABLE I.

Controller parameters, filter parameters and the performance measure of this study

\begin{tabular}{|c|c|c|c|c|c|c|c|c|c|c|}
\hline Process & Method & Iteration & $\mathbf{K}_{\mathbf{p}}$ & $\mathbf{K}_{\mathbf{i}}$ & $\mathbf{K}_{\mathbf{d}}$ & $\mathbf{T}_{\mathbf{f}}$ & ISE & IAE & $\mathbf{M}_{\mathbf{p}}$ & $\mathbf{T}_{\mathrm{s}}$ \\
\hline \multirow{7}{*}{ Process 1} & $\mathrm{HC}$ [24] & - & 0.5650 & 0.0460 & 0.3435 & 12.276 & 29.27 & 5.410 & 0.000 & 21.4 \\
\hline & $\mathrm{SSC}$ [25] & - & 0.5480 & 0.0493 & 0.5611 & 11.117 & 25.60 & 5.060 & 0.033 & 20.7 \\
\hline & $\begin{array}{l}\text { Visioli } \\
{[26]}\end{array}$ & - & 0.6240 & 0.0540 & 0.7245 & 11.551 & 21.30 & 4.615 & 0.000 & 23.7 \\
\hline & JSH [27] & - & 0.3840 & 0.0127 & 0.0000 & 30.301 & 293.9 & 17.14 & 0.000 & 35.3 \\
\hline & PSO & 76 & 0.4403 & 0.0217 & 0.3133 & 20.290 & 122.0 & 11.04 & 0.016 & 28.4 \\
\hline & IPSO & 68 & 0.5110 & 0.0230 & 0.5887 & 22.217 & 103.6 & 10.18 & 0.000 & 27.1 \\
\hline & $\mathrm{BFO}$ & 82 & 0.5190 & 0.0302 & 0.5017 & 17.185 & 65.30 & 8.081 & 0.000 & 35.4 \\
\hline
\end{tabular}




\begin{tabular}{|l|l|l|l|l|l|l|l|l|l|l|}
\hline & Hybrid & 67 & 0.6361 & 0.0471 & 0.3257 & 13.505 & 27.66 & 5.260 & 0.000 & 24.6 \\
\hline \multirow{5}{*}{ Process 2 } & HC [24] & - & 1.7920 & 0.1442 & 0.8602 & 12.425 & 47.71 & 6.907 & 0.000 & 24.8 \\
\cline { 2 - 10 } & PC [21] & - & 1.5860 & 0.1322 & 0.7597 & 12.000 & 56.89 & 7.542 & 0.146 & 29.4 \\
\cline { 2 - 10 } & LLP [28] & - & 1.9490 & 0.1616 & 1.6099 & 12.063 & 38.03 & 6.167 & 0.000 & 23.1 \\
\cline { 2 - 10 } & PSO & 61 & 1.6502 & 0.2161 & 1.0061 & 7.6363 & 21.39 & 4.625 & 0.345 & 27.7 \\
\cline { 2 - 10 } & IPSO & 53 & 1.4462 & 0.1142 & 1.0644 & 12.664 & 74.91 & 8.655 & 0.221 & 28.3 \\
\cline { 2 - 10 } & BFO & 78 & 2.0772 & 0.1865 & 1.2290 & 11.138 & 28.25 & 5.316 & 0.000 & 23.9 \\
\cline { 2 - 10 } & Hybrid & 49 & 1.9518 & 0.2103 & 1.0643 & 9.2810 & 22.49 & 4.742 & 0.024 & 21.1 \\
\hline
\end{tabular}

Process 3: Jacketed Continuous Stirred Tank Reactor (CSTR) studied by Bequette [29] can be represented by the following equations;

$$
\begin{aligned}
& \frac{\mathrm{dC}_{\mathrm{A}}}{\mathrm{dt}}=\mathrm{f}_{1}\left(\mathrm{C}_{\mathrm{A}}, \mathrm{T}, \mathrm{T}_{\mathrm{j}}\right)=\frac{\mathrm{F}}{\mathrm{V}}\left(\mathrm{C}_{\mathrm{Af}}-\mathrm{C}_{\mathrm{A}}\right)-\mathrm{k}_{0} \exp \left(\frac{-\Delta \mathrm{E}}{\mathrm{RT}}\right) \mathrm{C}_{\mathrm{A}} \\
& \frac{\mathrm{dT}}{\mathrm{dt}}=\mathrm{f}_{2}\left(\mathrm{C}_{\mathrm{A}}, \mathrm{T}, \mathrm{T}_{\mathrm{j}}\right)=\frac{\mathrm{F}}{\mathrm{V}}\left(\mathrm{T}_{\mathrm{f}}-\mathrm{T}\right)+\frac{(-\Delta H)}{\rho C_{p}} \mathrm{k}_{0} \exp \left(\frac{-\Delta \mathrm{E}}{\mathrm{RT}}\right) \mathrm{C}_{\mathrm{A}}-\frac{U A}{V \rho C_{p}}\left(T-T_{j}\right) \\
& \frac{\mathrm{dT}_{\mathrm{j}}}{\mathrm{dt}}=\mathrm{f}_{3}\left(\mathrm{C}_{\mathrm{A}}, \mathrm{T}, \mathrm{T}_{\mathrm{j}}\right)=\frac{\mathrm{F}_{\mathrm{j}_{f}}}{\mathrm{~V}_{\mathrm{j}}}\left(T_{j f}-T_{j}\right)+\frac{U A}{V_{j} \rho_{j} C_{p_{j}}}\left(T-T_{j}\right)
\end{aligned}
$$

Eqn. 15 - 17 represents the modeling equations of the case study which discuss the production of propylene glycol by the hydrolysis of propylene oxide with sulphuric acid as a catalyst.

TABLE II.

Modelling parameters of the CSTR

\begin{tabular}{ll}
\hline \multicolumn{1}{c}{ Parameter } & \multicolumn{1}{c}{ Value } \\
\hline Activation factor $\left(\mathrm{E}_{\mathrm{a}}\right)$ & $32,400 \mathrm{Btu} / \mathrm{lbmol}$ \\
Frequency factor $\left(\mathrm{k}_{\mathrm{o}}\right)$ & $16.96 \times 10^{12} \mathrm{hr}^{-1}$ \\
Heat of reaction $(-\Delta \mathrm{H})$ & $39000 \mathrm{Btu} / \mathrm{lbmol} \mathrm{PO}$ \\
$\mathrm{U}$ & $75 \mathrm{Btu} / \mathrm{hr} \mathrm{ft}^{2}{ }^{\circ} \mathrm{F}$ \\
$\rho \mathrm{C}_{\mathrm{p}}$ & $53.25 \mathrm{Btu} / \mathrm{ft}^{3}{ }^{\circ} \mathrm{F}$ \\
$\mathrm{R}$ & $1.987 \mathrm{Btu} / \mathrm{lbmol}^{\circ} \mathrm{F}$ \\
Residence time $(\mathrm{V} / \mathrm{F})$ & $15 \mathrm{~min}=0.25 \mathrm{hr}$ \\
$\mathrm{C}_{\mathrm{Af}}$ & $0.132 \mathrm{lbmol} / \mathrm{ft}^{3}$ \\
$\mathrm{~T}_{\mathrm{f}}$ & $60^{\circ} \mathrm{F}=519.67 \mathrm{R}$ \\
$\mathrm{V}_{\mathrm{j}} / \mathrm{V}$ & 0.25 \\
$\mathrm{~T}_{\mathrm{jf}}$ & $0{ }^{\circ} \mathrm{F}$ \\
$\rho_{\mathrm{i}} \mathrm{C}_{\mathrm{pi}}$ & $55.6 \mathrm{Btu} / \mathrm{ft}^{3}{ }^{\circ} \mathrm{F}$ \\
\hline
\end{tabular}

The process transfer function model relating the jacket flow rate to the reactor temperature is

$$
G_{p}(s)=\frac{-4.4747 s-37.94}{s^{3}+9.332 s^{2}+16.89 s-34.45} x e^{-0.5 s}
$$

The robust stability of the CSTR model is analysed using the Kharitonov's theorem [30]. This method provides a necessary and sufficient analysis test for the robust stability of polynomials with perturbed coefficients.

Let the closed loop system with the above characteristic equation are defined by in the interval $p_{i}^{L} \leq p_{i} \leq p_{i}^{U}$ with a lower and higher bond of parameters of $p_{i}$ with $\mathrm{i}=0,1,2 \ldots 6$. According to Kharitonov's theorem, every characteristic equation in the interval family will be stable if the following four Kharitonov polynomials are Hurwitz:

$$
\begin{aligned}
& \mathrm{K}_{11}(\mathrm{~s})=\mathrm{p}_{0}^{\mathrm{L}}+\mathrm{p}_{1}^{\mathrm{L}} \mathrm{s}+\mathrm{p}_{2}^{\mathrm{U}} \mathrm{s}^{2}+\mathrm{p}_{3}^{\mathrm{U}} \mathrm{s}^{3}+\mathrm{p}_{4}^{\mathrm{L}} \mathrm{s}^{4}+\mathrm{p}_{5}^{\mathrm{L}} \mathrm{s}^{5}+\ldots \\
& \mathrm{K}_{12}(\mathrm{~s})=\mathrm{p}_{0}^{\mathrm{L}}+\mathrm{p}_{1}^{\mathrm{U}} \mathrm{s}+\mathrm{p}_{2}^{\mathrm{U}} \mathrm{s}^{2}+\mathrm{p}_{3}^{\mathrm{L}} \mathrm{s}^{3}+\mathrm{p}_{4}^{\mathrm{L}} \mathrm{s}^{4}+\mathrm{p}_{5}^{\mathrm{U}} \mathrm{s}^{5}+\ldots \\
& \mathrm{K}_{21}(\mathrm{~s})=\mathrm{p}_{0}^{\mathrm{U}}+\mathrm{p}_{1}^{\mathrm{L}} \mathrm{s}+\mathrm{p}_{2}^{\mathrm{L}} \mathrm{s}^{2}+\mathrm{p}_{3}^{\mathrm{U}} \mathrm{s}^{3}+\mathrm{p}_{4}^{\mathrm{U}} \mathrm{s}^{4}+\mathrm{p}_{5}^{\mathrm{L}} \mathrm{s}^{5}+\ldots \\
& \mathrm{K}_{22}(\mathrm{~s})=\mathrm{p}_{0}^{\mathrm{U}}+\mathrm{p}_{1}^{\mathrm{U}} \mathrm{s}+\mathrm{p}_{2}^{\mathrm{L}} \mathrm{s}^{2}+\mathrm{p}_{3}^{\mathrm{L}} \mathrm{s}^{3}+\mathrm{p}_{4}^{\mathrm{U}} \mathrm{s}^{4}+\mathrm{p}_{5}^{\mathrm{U}} \mathrm{s}^{5}+\ldots
\end{aligned}
$$


As the process parameters (gain, time constant and time delay) are perturbed, closed-loop stability changes. The CSTR model for the perturbed process parameters around their nominal values with the polynomials $\left(\mathrm{K}_{11}, \mathrm{~K}_{12}\right.$, $\mathrm{K}_{21}, \mathrm{~K}_{22}$ ) in $\mathrm{s}=\mathrm{j} \omega$ plane were checked for Hurwitz condition.

Fig 6. Shows the Kharitonov's rectangles for the CSTR model in S-plane, from this plot, it is observed that the open loop system with the perturbed process parameters shows that it is in unstable operating region.

An optimal controller tuning for this process is then proposed with the evolutionary methods and the corresponding controller and the filter parameters are presented in Table 1. Fig 7 shows the servo response of the CSTR temperature profile. The hybrid algorithm based controller performs better compared to PSO, IPSO and BFO tuned controller. The performance measure values are clearly presented in Table 1.

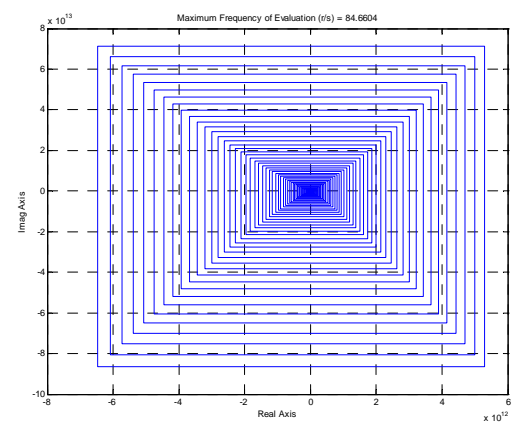

Fig. 6. Kharitonov rectangles for the CSTR model in S plane

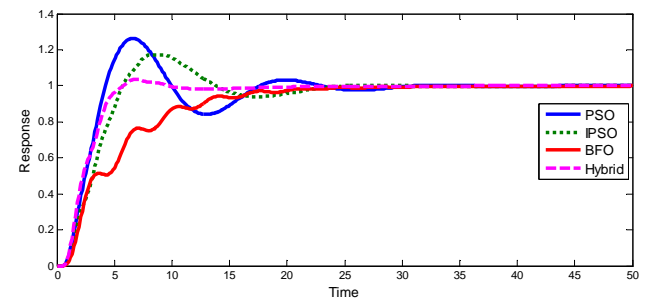

Fig.7. Servo response of Jacketed CSTR

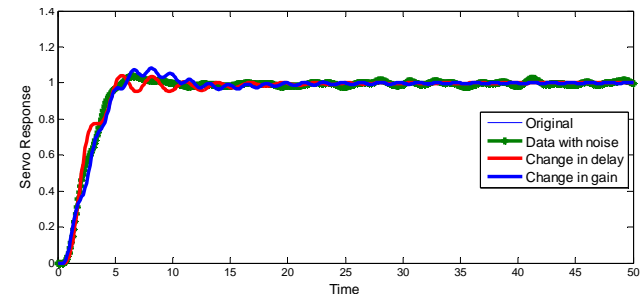

Fig. 8. Servo response of CSTR with perturbed process parameters

The hybrid algorithm tuned set-point filter with the PID structure is then tested for the robustness by applying a $10 \%$ increase in the delay, $25 \%$ increase in the gain and a measurement noise (band limited white noise) with a noise power of 0.001 . From Fig 8 . it is observed that, the controller provides a smooth response for the CSTR model with the perturbed process parameters.

\section{b. TITO system}

Process 4: The proposed controller design procedure is then tested on the WB model [14].

$$
\left[\begin{array}{l}
y_{1}(s) \\
y_{2}(s)
\end{array}\right]=\left[\begin{array}{ll}
\frac{12.8 e^{-s}}{16.7 s+1} & \frac{-18.9 e^{-3 s}}{21 s+1} \\
\frac{6.6 e^{-7 s}}{10.9 s+1} & \frac{-19.4 e^{-3 s}}{14.4 s+1}
\end{array}\right]\left[\begin{array}{l}
u_{1}(s) \\
u_{2}(s)
\end{array}\right]
$$

Eqn. 23 shows the model of WB bench mark system. Initially, the IPSO based search is attempted to identify the optimal controller values, later BFO, hybrid algorithm and FA based search are considered. During the controller design process, the simulation time ' $T$ ' is assigned as $500 \mathrm{sec}$. A unit step signal is applied as the reference signal during $P I D_{1}$ design and the input signal is considered as ' 0 ' for $P I D_{2}$ tuning. 
TABLE III.

Optimized PID values for WB model

\begin{tabular}{|c|c|c|c|c|c|c|c|}
\hline \multirow{2}{*}{ Process } & \multirow{2}{*}{ Method } & \multicolumn{3}{|c|}{ Top Product } & \multicolumn{3}{c|}{ Bottom product } \\
\cline { 3 - 8 } & & $\mathrm{K}_{\mathrm{p}}$ & $\mathrm{K}_{\mathrm{i}}$ & $\mathrm{K}_{\mathrm{d}}$ & $\mathrm{K}_{\mathrm{p}}$ & $\mathrm{K}_{\mathrm{i}}$ & $\mathrm{K}_{\mathrm{d}}$ \\
\hline \multirow{4}{*}{ WB } & $\mathrm{IPSO}$ & 0.4884 & 0.0476 & 0.0791 & -0.0418 & -0.0108 & -0.0611 \\
\cline { 2 - 8 } & $\mathrm{BFO}$ & 0.6011 & 0.0520 & 0.0602 & -0.0592 & -0.0102 & -0.0838 \\
\cline { 2 - 8 } & Hybrid & 0.5177 & 0.0503 & 0.0571 & -0.0616 & -0.0139 & -0.0588 \\
\cline { 2 - 8 } & $\mathrm{FA}$ & 0.5811 & 0.0628 & 0.0527 & -0.0591 & -0.0120 & -0.1018 \\
\hline
\end{tabular}

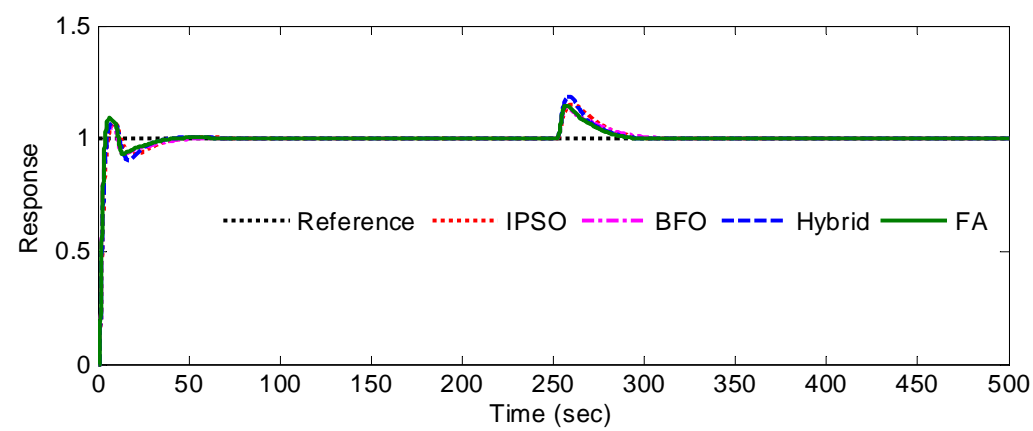

Fig. 9. Response of top product

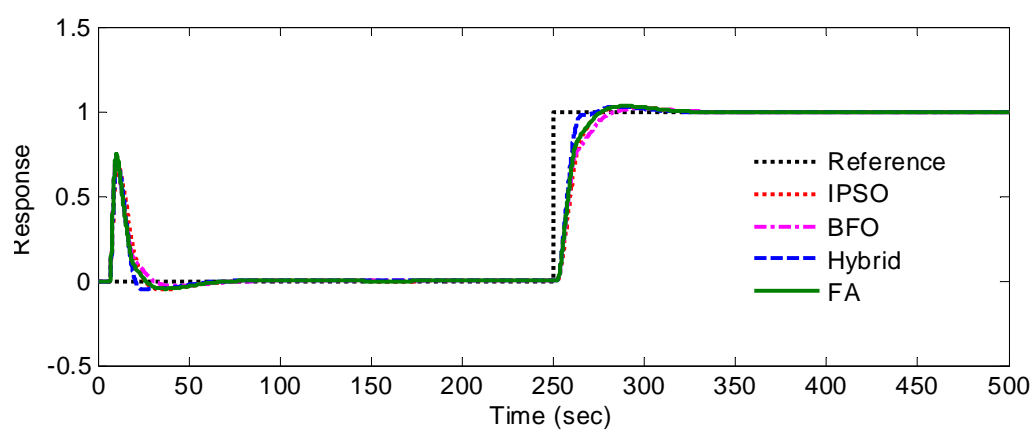

Fig. 10. Response of bottom product

TABLE IV.

Error values for WB model

\begin{tabular}{|c|c|c|c|c|c|}
\hline \multirow{2}{*}{ Process } & \multirow{2}{*}{ Method } & \multicolumn{2}{|c|}{ Top Product } & \multicolumn{2}{c|}{ Bottom product } \\
\cline { 3 - 6 } & & ISE & IAE & ISE & IAE \\
\hline \multirow{4}{*}{ WB } & IPSO & 0.0072 & 0.0851 & 21.5800 & 4.6450 \\
\cline { 2 - 6 } & BFO & 0.0061 & 0.0779 & 24.1900 & 4.9180 \\
\cline { 2 - 6 } & Hybrid & 0.0065 & 0.0805 & $\mathbf{1 3 . 0 3 0 0}$ & $\mathbf{3 . 6 0 9 0}$ \\
\cline { 2 - 6 } & FA & $\mathbf{0 . 0 0 4 1}$ & $\mathbf{0 . 0 6 4 5}$ & 17.4800 & 4.1810 \\
\hline
\end{tabular}

Table 3 presents the optimised controller parameters and Table 4 presents the performance measure values obtained with heuristic algorithm tuned controllers. In order to confirm the smooth reference tracking performance, a unity step signal is assigned as the reference for the bottom product at $\mathrm{T}=250$ and the process response values are recorded as shown in Fig. 9 and 10. From this result, it is confirmed that, proposed approach is efficient in offering the better PID parameters for the TITO system.

\section{CONCLUSION}

In this work, heuristic approach based controlling tuning problem is addressed for a class of SISO and a TITO system. A detailed comparative study between the PSO, IPSO, BFO, hybrid algorithm and FA are presented. In this work, a well known unstable SISO process models are considered and the PID controller values are designed. The performances of the heuristic algorithms are assessed based on the time domain performance measures. The proposed approach is also validated on the classical tuning procedures existing in the literature. Finally, the robustness of the designed controller is confirmed using the Kharitonov's approach. The simulation result confirms that, the proposed approach offers better result on the SISO process models. Finally, the 
advantage of the heuristic approach is then confirmed using the WB distillation process existing in the literature. From this paper, it is confirmed that, heuristic algorithm based approaches are very efficient in designing the PID controller for the SISO and TITO process models.

\section{REFERENCES}

[1] V. Rajinikanth, and K. Latha, "Controller Parameter Optimization for Nonlinear Systems Using Enhanced Bacteria Foraging Algorithm," Applied Computational Intelligence and Soft Computing, vol. 2012, Article ID 214264, 12 pages, 2012.

[2] K. Latha, V. Rajinikanth, and P. M. Surekha, "PSO-Based PID Controller Design for a Class of Stable and Unstable Systems," ISRN Artificial Intelligence, vol. 2013, Article ID 543607, 11 pages, 2013.

[3] V. Rajinikanth, and K. Latha, "Setpoint weighted PID controller tuning for unstable system using heuristic algorithm," Archives of Control Sciences, vol.22, no.4, pp. 481-505, 2012.

[4] V. Rajinikanth, and K. Latha, "Bacterial foraging optimization algorithm based PID controller tuning for time delayed unstable system," The Mediterranean Journal of Measurement and Control, vol.7, no.1, pp. 197-203, 2011.

[5] K. Suresh Manic, S. Devakumar, V. Vijayan, and V. Rajinikanth, "Design of Centralized PI Controller for Interacting Conical Tank System,” Indian Journal of Science and Technology, vol.9, no.12, pp. 89920, 2016.

[6] V. Rajinikanth, and K. Latha, "Optimization of PID controller parameters for unstable chemical systems using soft computing technique," International Review of Chemical Engineering, vol.3, no.3, pp. 350-358, 2011.

[7] R. Kotteeswaran, and L. Sivakumar, "Optimal Tuning of Decentralized PI Controller of Nonlinear Multivariable Process Using Archival Based Multiobjective Particle Swarm Optimization,” Modelling and Simulation in Engineering, vol. 2014, pp. 1-16, 2014.

[8] W.D. Chang, and S.P. Shin, "PID controller design of nonlinear systems using an improved particle swarm optimization approach," Communications in Nonlinear Science and Numerical Simulation, Elsevier, vol. 15, no.11, pp. 3632-3639, 2010.

[9] V. Rajinikanth, and K. Latha, "Tuning and Retuning of PID Controller for Unstable Systems Using Evolutionary Algorithm," ISRN Chemical Engineering, vol. 2012, Article ID 693545, 11 pages, 2012.

[10] V. Rajinikanth, and K. Latha, "PID controller tuning for magnetic suspension system using evolutionary algorithm," International Review of Mechanical Engineering, vol.6, no.5, pp. 988-995 2012.

[11] Wael. M. Korani, Hassen Taher Dorrah, and Hassan M. Emara, "Bacterial foraging oriented by particle swarm optimization strategy for PID tuning," Proceedings of the $8^{\text {th }}$ IEEE international conference on Computational intelligence in robotics and automation, pp. 445-450, 2008

[12] A. Rajasekhar, A. Abraham, and V. Snasel, "A Hybrid Bacterial Foraging - PSO Algorithm Based Tuning of Optimal FOPI Speed Controller,” Acta Montanistica Slovaca, vol.16,no.1, pp.55-65, 2011.

[13] K. Suresh Manic, V. Rajinikanth, Sarath Ananthasivam, Uma Suresh, "Design of Controller in Double Feedback Control Loop-An Analysis with Heuristic Algorithms," Chemical Product and Process Modeling, vol.10, no.4, pp. 253-262, 2015.

[14] R. Sivakumar, V. Rajinikanth, and D. Sankaran, "Multi-loop PI controller design for TITO system: an analysis with BA, FA, PSO and BFO," Australian Journal of Basic Applications Sciences, vol.9, no.16, pp.249-54, 2015.

[15] V. Rajinikanth, and Suresh Chandra Satapathy, "Design of controller for automatic voltage regulator using teaching learning based optimization," Procedia Technology, vol. 21, pp. 295-302, 2015.

[16] J. Kennedy, and R. Eberhart, "Particle Swarm Optimization," in proceedings of IEEE International Conference on Neural, pp. 1942$1948,1995$.

[17] K. M. Passino, "Biomimicry of bacterial foraging for distributed optimization and control," IEEE Control Systems Magazine, pp.52$67,2002$.

[18] X.-S. Yang, "Firefly algorithms formultimodal optimization," in Stochastic Algorithms: Foundations and Applications, Lecture Notes in Computer Science, vol. 5792, pp. 169-178, 2009.

[19] N. S.M. Raja, V. Rajinikanth, and K. Latha, "Otsu Based Optimal Multilevel Image Thresholding Using Firefly Algorithm," Modelling and Simulation in Engineering, vol. 2014, Article ID 794574, 17 pages, 2014.

[20] V. Rajinikanth, and M.S. Couceiro, "RGB histogram based color image segmentation using firefly algorithm," Procedia Computer Science, vol.46, pp.1449-1457, 2015.

[21] R. Padma Sree, and M. Chidambaram, "Control of Unstable Systems," Narosa Publishing House, India, 2006.

[22] V. Rajinikanth, and K. Latha, "I-PD controller tuning for unstable system using bacterial foraging algorithm: a study based on various error criterion," Applied Computational Intelligence and Soft Computing, vol. 2012, Article ID 329389, 10 pages, 2012.

[23] V. Rajinikanth, and K. Latha, "Internal model control-proportional integral derivative controller tuning for first order plus time delayed unstable systems using bacterial foraging algorithm," Scientific Research and Essays, vol.7, no.40, pp. 3406-3420, 2012.

[24] H. P. Huang, and C.C. Chen, “Auto-tuning of PID controllers for second order unstable process having dead time,".J. Chem. Eng. Jpn. , vol.32, no.4, pp.486-497, 1999.

[25] R. Padma Sree, M.N. Srinivas, and M. Chidambaram, "A simple method of tuning PID controllers for stable and unstable FOPDT systems," Comput. Chem. Eng., vol.28, pp. 2201-2218, 2004.

[26] A. Visioli, "Optimal tuning of PID controllers for integral and unstable processes," IEE Proc. Control Theory Appl., vol.148, no.2, pp. $180-184,2001$.

[27] C.S. Jung, H.K. Song, and J.C. Hyun, “A direct synthesis tuning method of unstable first-order-plus-time-delay processes,” J. Process Control, vol.9, pp. 265-269, 1999 .

[28] Y. Lee, J. Lee, and S. Park, "PID controller tuning for integrating and unstable processes with time delay," Chem. Eng. Sci. , vol.55, pp. 3481-3496,2000.

[29] B. Wayne Bequette, "Process Control - Modeling, Design and Simulation," Prentice - Hall of India Pvt Ltd, 2003.

[30] V.L. Kharitonov, "Asymptotic stability of an equilibrium position of a family of systems of differential equations," Differentsialnye uravneniya, vol. 14, pp. 2086-2083, 1978 